\title{
Del clic al Congreso* \\ (La influencia de Internet en la ciudadanía y en el Estado)
}

\author{
Jorge Francisco Aguirre Sala**
}

Recibido: 2 de mayo de 2013 - Aprobado: 7 de junio de 2013

\begin{abstract}
Resumen
Los representantes políticos con excesiva autonomía y falta de deliberación co-legislativa con sus representados provocan inconformidades que desean influir ante el Estado. Los mass media tradicionales (televisión, periódicos, etc.) y la Web 1. secundaron la distancia entre ambos porque redujeron al electorado a meros receptores. Pero los new media de la Web 2.0 (Blogs, Facebook, Wikis, Twitter, etc.) pretenden superar esos límites y disolver, más que rebasar, las fronteras fijas y estáticas del quehacer político ciudadano en Internet. Así, los primeros suponían la democracia y la búsqueda de información, mientras los nuevos obsequian información y exigen la democracia.
\end{abstract}

Palabras clave: tecnología participativa, activismo, democracia digital.

* Artículo de reflexión, producto del proyecto de investigación El derecho de los ilegítimos, [UDEM-DIEX-2010-PR 085] avalado y financiado por la Universidad de Monterrey, México en el contexto de la investigación en Humanidades sobre Filosofía Social y de la Comunicación.

** Doctor en Filosofía y especialista en Psicología Terapéutica. Actualmente es docente en la Universidad de Monterrey-México. Correo electrónico: jorge.francisco.aguirre@udem.edu.mx. 


\title{
From the click to the Congress (The Influence of Internet on citizens and the State)
}

\begin{abstract}
Political representatives with excessive autonomy and lack of co-legislative deliberation with the people they represent provoke a discomfort que desean influir ante el Estado. Traditional mass media (television, newspapers, etc.) and Web 1 seconded the distance between both media since they reduced the voters to simple receivers. But the intention of new media of the Web 2.0 (Blogs, Facebook, Wikis, Twitter, etc.) is to overcome such boundaries and to dissolve -much more than to surpass- the fixed and static frontiers of the citizens' political performance on the Internet. In this way, the first ones were focused on democracy and the search for information, while the new ones provide information and demand democracy.
\end{abstract}

Key words: participative technology; activism; digital democracy. 


\section{Introducción}

La participación política a través de las tecnologías de información y comunicación (TIC) puede concebirse, a grandes rasgos, de dos modos: la protesta por medio del activismo y la participación ciudadana con autonomía del Estado. El primero posee mayor popularidad porque implica un activismo de reacción, es decir, resulta muy emotivo y, aunque a veces es efímero, generalmente es intenso. Movimientos como La primavera árabe, Los indignados o el Occupy movement, aunados a actividades de hackers, bloqueos, exhibición y denuncias desde Anonymous y WikiLeaks que han puesto en jaque a gobiernos, consorcios comerciales y corporaciones financieras, son atractivos y buenos ejemplos de este modo de participar políticamente. Sin embargo, no dejan de ser meras reacciones de protesta que devienen en activismo. De hecho son conocidas como "Clic Activismo" (Henríquez, 2011: 29) y se limitan a peticiones, boicots, marchas, ocupación de edificios, plazas o fábricas, exhortos a huelgas y paros, y demás formas de desobediencia civil que no siempre transforman las condiciones sociales de manera permanente y general. El segundo modo de participación es el involucramiento ciudadano, con autonomía del Estado, que busca la planeación programática de las políticas públicas y particularmente todo aquello que pueda influir en el Estado para institucionalizar mecanismos de participación. Estos tienen entre sus principales objetivos definir planes, programas y presupuestos de las acciones gubernamentales. También pueden incluir plebiscitos, referéndums, revocaciones de mandato y derecho a veto cuando una decisión gubernamental afecta derechos ganados por la ciudadanía. Postill considera el primer modo de participación "activismo banal" (2011: 51) por la reducción local de sus enfoques. Es decir, atienden de uno a uno asuntos muy particulares, intentando influir en la agenda pública pero de manera circunstancial y no estructural. Sin duda la adjetivación de Postill es discutible. Sin embargo, en ambos modos de participación es necesario analizar la influencia que reciben de las TIC y, a su vez, los logros en la influencia circunstancial o estructural que ejerce en el Estado.

\section{Metodología}

Análisis crítico conceptual de las diversas nociones involucradas en el estudio de la participación ciudadana y las vías de comunicación vía Internet (activismo, participación, influencia) como método cualitativo. Siguiendo las bases hermenéuticas se hace una comparación e interpretación de los alcances y posibilidades de las antiguas y nuevas tecnologías de información y comunicación en la reciprocidad asimétrica entre representantes políticos y ciudadanos representados.

\section{Lo local va hacia el centro}

Cuando nos preguntamos qué tanto podemos influir en una decisión estatal al acudir a un mitin o subiendo a la Web un Twitter, hacemos una pregunta que también desafía el cálculo político del Gobierno y las categorías predictivas de los científicos sociales. El Gobierno es desafiado porque las demandas ciudadanas insatisfechas representan el riesgo de protestas inmediatas o la futura participación política de un voto de resenti- 
miento que negará la reelección a los responsables políticos del descontento. Pero los asesores políticos aniquilan cualquier malestar en los responsables al argumentar que el asunto es mínimamente local y no trascenderá a las mayorías que deciden las elecciones. Además, están seguros de que 'no existe una red social homogénea, pues demuestran una pluralidad de sociedades diferenciadas por la naturaleza de la interacción, los discursos y la articulación de intereses de campo' (Postill, 2011). Aun cuando la ciudadanía intente homogeneizarse por un interés político común y con una comunicación efectiva como ofrecen las TIC de generación Web 2.0, los expertos consideran que no habrá mayores dificultades. Por ejemplo, Postill (2011) explica que las relaciones entre la participación ciudadana organizada con propósitos locales opera frente al Gobierno como el modelo de una "T" invertida. El eje vertical representa al Gobierno con las regulaciones federales, estatales y locales ubicadas gradualmente de arriba a abajo. El eje horizontal representa la gobernanza en el orden local, con el sector del voluntariado a la izquierda del eje vertical, el concejo municipal en la intersección, y el sector privado a la derecha. Siguiendo este modelo, Postill concluye que ni por los teóricos ni por los activistas de Internet habrá efectos en la estructura jerárquica del Estado moderno capturados en la "T" invertida. La opinión de Postill se suma a la de Crossley (2002) quien prácticamente distingue las áreas de protesta y activismo de aquellas que producen avances en una cultura política democrática, distinción útil a ambos autores para desacreditar las protestas y el activismo, ya que entre las propuestas y la cultura democrática los cambios son desiguales, poseen diferentes grados de evolución, aceptación social e incorporación política.

En efecto, los avances democráticos del activismo son muy distintos a los de la cultura política. En el activismo las acciones son circunstanciales: un asunto debe emerger a la agenda política y una vez resuelto o disuelto no quedará más vestigio que su vínculo con otros problemas pendientes. Cuando el activismo de este tipo opera con la Web 2.0 presenta un nuevo desafío al gobierno y a los científicos sociales, porque la ciudadanía que protesta, en efecto, no es homogénea y, en consecuencia, al Gobierno se le dificulta encontrar grupos ideológicos, clases sociales, instituciones únicas (organizaciones no gubernamentales, frentes, contingentes, etc.) o focos de atención, etc., y, por tanto, se complican las maneras de presentarles resistencia o criminalizarlos.

En contraste con las opiniones anteriores, Vattimo ya había profetizado en La sociedad transparente (1990) que los mass media contemporáneos, con la emergencia de Internet, eran un arma de doble filo: lo mismo podían ponerse al servicio de la hegemonía que ponerse al servicio de las culturas periféricas para emanciparlas. Pues bien, así como los antiguos mass media colonizaban la esfera pública en la privada, los new media de la Web 2.0 invierten esa ruta y buscan elevar la esfera privada hacia la agenda pública. Con ello, también intentan superar las fragmentaciones de quienes no logran establecerse como mayorías. Los cambios graduales y, en su mayoría semipacíficos, de varios regímenes políticos mundiales han mostrado el camino de la periferia al centro: iniciaron con logros electorales de la oposición en los órdenes municipales o locales, después continuaron ganando estados o provincias y en un buen número de casos han culminado cambiando de actores o partidos políticos en los gobiernos federales o países completos. México, 
Estados Unidos, Francia, Chile y algunas provincias autónomas de España, todos ellos con sus alternancias, son algunos ejemplos de las últimas décadas. Sin lugar a dudas, las campañas digitales del presidente Obama en Estados Unidos o del presidente Peña Nieto en México muestran la incidencia de los new media en la participación ciudadana.

\section{La Web en el quehacer ciudadano}

Pero lograr que la población se convierta en una ciudadanía activa no es fácil, menos aún si se desea establecer una interacción entre gobernantes y gobernados que han quedado en condiciones asimétricas por las deficiencias democráticas y comunicativas de la representatividad y, mucho menos aún, si los gobernados se encuentran en situaciones vulnerables. Aquí se hace significativo el papel de las redes sociales entendidas como nuevos medios informativos, de comunicación y convocatoria porque los medios masivos de comunicación (mass media: cine, radio, periódicos, televisión), que generan la opinión pública, han sido las redes coptadoras de las imágenes de confianza de los representantes políticos, de las alternancias en un mismo statu quo, a la vez que se constituyeron en el coto de la discusión pública. Ellos elevan o hunden las opiniones políticas, intervienen en los procesos electorales y ofrecen un sinnúmero de fuentes de información a los electores, de manera que, en efecto, estos creen que poseen la democracia y lo que deben buscar es la información, la cual les parece encontrar validada en la importancia de los "líderes de opinión" y en sospechosas encuestas de opinión pública o tendencias electorales. En la práctica, los mass media tradicionales han limitado (al colonizar la esfera pública en la privada) la participación ciudadana a un mero receptor pasivo de información. También lo hicieron así los new media de la Web 1.0 (listas de E-mail y teléfono móvil con aplicaciones). Pero los new media de la Web 2.0 empiezan a revertir la tendencia de colonización de las versiones anteriores.

En un trabajo reciente, Postill (2012) explica tres estrategias que encontró en diversos movimientos de activistas para llamar la atención e involucrar a los ciudadanos en la participación política. Las tres modalidades corresponden principalmente a Twitter y quizá podríamos extenderlas secundariamente a los Web-blogs, y, por tanto, (como se verá adelante en una tabla comparativa) son más propias para la movilización que para la deliberación, la difusión y el crecimiento o la colaboración, protección y organización políticas, aunque sin duda contribuyen a la cultura democrática.

A la primera estrategia la denomina "jugar el algoritmo". Para que el Twitter atrape la atención y extienda su capacidad de movilización es necesario que sus usuarios ejecuten la función de "sigue tus intereses". Ello permitirá hacer de la campaña activista una tendencia regular en las TIC. Postill se apoya en la investigación de Cullum (2010) que reporta el algoritmo de tendencias de Twitter. En este algoritmo demuestra que los temas o tendencias son favorecidos por la novedad y el volumen. La idea consiste en aumentar la novedad a través de los líderes activistas no oficiales con frecuentes cambios en las palabras clave de la campaña y, consecuentemente, conseguir el aumento de volumen al animar a los seguidores a retwittear el hashtag (palabra clave) recién acordado hasta 
constituirlo en una "tendencia" que alcanza a un público más amplio. Esta estrategia es útil para llamar la atención de la ciudadanía sobre las tendencias más socorridas, las causas sociales en lucha y para suplir, en medida mínima, la escasez de civismo que paraliza la participación política.

La segunda estrategia se llama "\# recopilar los hechos". Consiste en la versión adaptada a Twitter del juego de Internet que popularizó en la red el actor Chuck Norris bajo la firma "Chuck Norris Facts". Esta estrategia en Twitter convierte una frase en un poderoso hashtag, es decir, una frase sirve como herramienta para encontrar, seguir, suscribir, organizar y tener listas de contactos públicos de una multiplicidad de usuarios que fecundan la discusión sobre un tema. Con ello se pueden elevar algunos asuntos a la cima de las tendencias en las TIC (no solo Twitter, sino también grupos de Facebook, Amigos Delicious, YouTube, Second Life, foros Web, grupos de listas, Webblogs y quisiéramos vaticinar también las plataformas de la Web 3.0), lo cual, en la cultura política, equivaldría a poner un asunto de la esfera privada en la agenda pública. Pues en la práctica cuando un tema alcanza las mayores audiencias en las tendencias (trending topics) aparece de manera automática en la página principal de los usuarios. Para la participación ciudadana, autónoma del Estado, es ventajosa, porque el hashtag no puede ser controlado ni retirado por el uso público y cuando es buscado por el usuario este encontrará el grupo de mensajes que lo han constituido, lo cual permite su pronta y eficiente incorporación a la deliberación pública del asunto.

La tercera estrategia es particularmente política: "twitteando la nación". Consiste en agrupar bajo un mismo interés político al máximo número posible de usuarios aunque pertenezcan a grupos distintos entre sí. Ello supera las críticas de los teóricos que consideran fragmentadas o insignificantes a las minorías que constituyen las audiencias ciudadanas que hacen uso de las plataformas de los new media. Los estudiosos de los fenómenos Web (Gee, Wenger), y los teóricos multiculturales de la ciencia política (particularmente Young) coinciden en el criterio de agrupación y pertenencia: la afinidad. La afinidad es la forma de ver, sentir, pensar y actuar en el mundo con el interés emancipatorio de superar la opresión. Cuando se "twittea la nación" se refuerzan los alcances culturales y políticos de una nación (no de un Estado), como lo mostraron las infiltraciones de Twitters y Blogs que lograron burlar la censura del Gobierno chino cuando Liu Xiaobo ganó el Premio Nobel de la Paz en 2010.

Las tres estrategias descritas pueden ubicarse en el marco del debate entre Malcolm Gladwell (2010) y Henry Jenkins (2010) sobre el poder movilizador de los blogs y sus efectos políticos. En ese marco teórico nos atrevemos a afirmar que los new media muestran la capacidad de superar las limitaciones de la tradicional participación ciudadana a través de la convocatoria de afinidad. Si bien puede suscribirse lo que ha dicho Jenkins: "son distintos los movimientos y las plataformas" (2010) y, por tanto, no debemos confundir los instrumentos de participación con la acción de la misma (dado que acudir a un mitin o subir un Twitter es diferente a ser coparticipe de una decisión estatal), también es cierto lo que ha dicho Gladwell sobre la falta de organización de las redes. Además, todos pode- 
mos coincidir en que no vivimos en una sola plataforma, sino entre diversas plataformas. De ahí que, aunque las redes carezcan de organización, jerarquía y centralización, no adolecen de afinidad vinculadora, conciencia de lazos débiles y sobre todo de facilidad para la coordinación comprometedora, como lo muestra Srinivasan (2009) cuando hace ver que todo activismo virtual puede contribuir a un activismo real con un simple: "pulse el botón para donar aquí".

El alcance de la Web en la participación ciudadana, como el camino de la periferia al centro y en la perspectiva de su influencia en el Estado, puede ilustrarse con los avances en materia de condición comunicativa, creación cultural e influencia política entre los mass media tradicionales, los new media y de la Web 1.0 a la Web 3.0. En el listado de los medios tradicionales se encuentran los diarios o periódicos, la radio, el cine y la televisión. En los new media, o tecnología de información y comunicación denominada también Web 2.0 -para distinguirla de la simple Internet o Web 1.0 donde solo cabía la relación unilateral emisor-receptor-, se hallan: el correo electrónico, el teléfono móvil con inclusión de Internet, los portales interactivos de Chats, foros, Blogs; el Facebook, el Twitter, las cuentas de You Tube, los Wikis, como particularmente los Wiki-leaks y la Wiki-pedia de colaboración abierta, las cuentas de Mp3, y el P2P (Peer to peer o red de pares que se constituye sin clientes ni servidores), por mencionar solo los sitios o redes no comerciales y de mayor vigencia, pues paralelamente a estos se existen las redes comerciales como Flickr, Tuenti, MySpace y un larguísimo etcétera. Toda esta tecnología (new media) podemos enfocarla a diversos tipos de incidencia digital en los portales electrónicos donde, a diferencia de los medios tradicionales, los usuarios pueden ser a la vez receptores y emisores, gracias a lo cual la participación ciudadana rebasa los límites de los mass media tradicionales y de la tradicional representatividad política. Las diferencias entre mass media y new media al respecto podemos visualizarlas en la siguiente tabla.

\section{Tabla 1}

\begin{tabular}{|l|l|}
\hline \multicolumn{2}{|l|}{$\begin{array}{l}\text { Diferencias de condición comunicativa para la participación ciudadana } \\
\text { Mass Media Tradicionales y New Media } \\
\text { (periódicos, cine, radio y televisión) (Facebook, Twitter, E-mail, Wikis, etc.) }\end{array}$} \\
\hline $\begin{array}{l}\text { Condicionados a la economía del mercado y la } \\
\text { planeación de reelección política }\end{array}$ & $\begin{array}{l}\text { Causados por el obsequio de software libre y } \\
\text { de contenidos sin compromisos }\end{array}$ \\
\hline $\begin{array}{l}\text { Utilizados sólo por profesionales y a veces } \\
\text { aceptan a amateurs }\end{array}$ & $\begin{array}{l}\text { Utilizados por amateurs que ven como iguales } \\
\text { a los profesionales }\end{array}$ \\
\hline Poseen barreras altas de ingreso & No tienen barreras de ingreso \\
\hline $\begin{array}{l}\text { Sólo los emisores son protagonistas: uno habla } \\
\text { y muchos escuchan, uno aparece y muchos } \\
\text { contemplan }\end{array}$ & $\begin{array}{l}\text { La propagación en "tiempo real" transforma } \\
\text { al receptor en protagonista: todos twittean, } \\
\text { bloguean, todos "suben" a todos }\end{array}$ \\
\hline $\begin{array}{l}\text { Buscan complacer a electores, clientes y con- } \\
\text { sumidores }\end{array}$ & $\begin{array}{l}\text { Cada usuario es un elector y potencial inter } \\
\text { locutor }\end{array}$ \\
\hline
\end{tabular}




\begin{tabular}{|c|c|}
\hline $\begin{array}{l}\text { Requieren de un aval público que los somete } \\
\text { a censura }\end{array}$ & $\begin{array}{l}\text { Carecen de censura y su registro multiplica los } \\
\text { enlaces en red }\end{array}$ \\
\hline $\begin{array}{l}\text { La censura "supone" los intereses de los } \\
\text { lectores }\end{array}$ & Los lectores (seguidores) son censura real \\
\hline $\begin{array}{l}\text { Carecen de sentido si no apoyan a un grupo } \\
\text { hegemónico }\end{array}$ & $\begin{array}{l}\text { Buscan sentido independientemente de su } \\
\text { impacto a grupos de poder }\end{array}$ \\
\hline Fracasan con poca audiencia & $\begin{array}{l}\text { Son indiferentes ante pocas respuestas y el in- } \\
\text { cremento de su valor es exponencial al número } \\
\text { de usuarios }\end{array}$ \\
\hline $\begin{array}{l}\text { Sólo los emisores dotan de valoración al medio } \\
\text { y sus contenidos }\end{array}$ & $\begin{array}{l}\text { El usuario interactivo genera utilidad, práctica } \\
\text { y valor }\end{array}$ \\
\hline $\begin{array}{l}\text { La emisión-recepción no transforma al conte- } \\
\text { nido ni al medio }\end{array}$ & $\begin{array}{l}\text { La participación genera un bien comunicativo } \\
\text { que mejora al contenido, al medio y al usuario }\end{array}$ \\
\hline $\begin{array}{l}\text { Sólo se dirigen al público, pues son coloniza- } \\
\text { dores de la esfera privada. }\end{array}$ & $\begin{array}{l}\text { Influyen en la audiencia y en el mismo medio, } \\
\text { pues elevan lo privado a lo público }\end{array}$ \\
\hline Su utilidad es sólo receptiva & $\begin{array}{l}\text { La utilidad es variada } \\
\text { Twitter: movilización } \\
\text { Blog: espacio deliberativo } \\
\text { Facebook: difusión y crecimiento } \\
\text { Web federada: colaboración, protección y } \\
\text { organización }\end{array}$ \\
\hline $\begin{array}{l}\text { Generan mega-relatos hegemónicos; imponen } \\
\text { modelos centralizados }\end{array}$ & $\begin{array}{l}\text { Destruyen los mega-relatos alienantes; cons- } \\
\text { truyen las periferias }\end{array}$ \\
\hline $\begin{array}{l}\text { Acotan la territorialidad y unifican las signifi- } \\
\text { caciones }\end{array}$ & $\begin{array}{l}\text { Provocan desterritorialización y ordenes sim- } \\
\text { bólicos e imaginarios libres }\end{array}$ \\
\hline $\begin{array}{l}\text { Construyen identidades ciudadanas uniformes } \\
\text { conforme a grupos empoderados }\end{array}$ & $\begin{array}{l}\text { Edifican ciudadanos en una gama de identida- } \\
\text { des emancipadas y diferenciadas }\end{array}$ \\
\hline $\begin{array}{l}\text { Los derechos mediáticos están reducidos a la } \\
\text { libertad de prensa y ésta es acotada por los } \\
\text { dueños de los medios y los intereses de quiénes } \\
\text { están en el Estado }\end{array}$ & $\begin{array}{l}\text { Los derechos mediáticos producen la apropia- } \\
\text { ción de nuevos derechos (e-educación genera } \\
\text { usuarios del e-gobierno, e-voto, e-participación } \\
\text { ciudadana) }\end{array}$ \\
\hline $\begin{array}{l}\text { Asumen que se posee democracia representa- } \\
\text { tiva y se busca información }\end{array}$ & $\begin{array}{l}\text { Obsequian información, difunden ideas y pro- } \\
\text { vocan la deliberación, así buscan la democracia } \\
\text { participativa }\end{array}$ \\
\hline
\end{tabular}

Fuente: elaboración propia a partir de Robert Metcalfe (1976), Brian Arthur (1989), Pascal Jollivet (2004) y Jay Rosen (2005).

Para completar lo anterior, las diferencias y avances desde la Web 1.0 hacia la Web 3.0 podremos visualizarlas en la siguiente tabla. 
Tabla 2. Principales características que distinguen la potencialidad de participación ciudadana en la evolución de las TIC desde la Web 1.0 hasta la Web 3.0

\begin{tabular}{|c|c|c|}
\hline Web 1.0 & Web 2.0 & Web 3.0 \\
\hline $\begin{array}{l}\text { Personas conectándose a la } \\
\text { Web }\end{array}$ & $\begin{array}{l}\text { Personas conectándose a per- } \\
\text { sonas }\end{array}$ & $\begin{array}{l}\text { Aplicaciones Web conectándo- } \\
\text { se a aplicaciones Web }\end{array}$ \\
\hline $\begin{array}{l}\text { Conexión exclusiva de emisor } \\
\text { a receptor }\end{array}$ & $\begin{array}{l}\text { Conexión bidireccional entre } \\
\text { emisores y receptores }\end{array}$ & $\begin{array}{l}\text { Conciencia de la Web Geo-es- } \\
\text { pacial }\end{array}$ \\
\hline Doble click & Anuncios inteligentes & $\begin{array}{l}\text { Autonomía respecto del na- } \\
\text { vegador }\end{array}$ \\
\hline Sitio de fotos "Ofoto" & Sitio de fotos "Flickr" & $\begin{array}{l}\text { Construcción de la Web Se- } \\
\text { mántica }\end{array}$ \\
\hline Servicio "Akamai" & $\begin{array}{l}\text { Programas para archivos como } \\
\text { "BitTorrent" }\end{array}$ & $\begin{array}{l}\text { Genera experiencia y cultura } \\
\text { política entre personas }\end{array}$ \\
\hline $\begin{array}{l}\text { Sitio web de descarga de mú- } \\
\text { sica, videos, textos }\end{array}$ & $\begin{array}{l}\text { Programas par a par para com- } \\
\text { partir música ("Napster"), pro- } \\
\text { piedad virtual ("Second Life") }\end{array}$ & Web Tercera dimensión \\
\hline Enciclopedia Británica en línea & Proyecto Wikipedia & Genera nueva información \\
\hline Sitos personales & Bitácoras electrónicas & $\begin{array}{l}\text { Aplicaciones y agentes de } \\
\text { usuarios }\end{array}$ \\
\hline Screen scraping & Servicios en red & Servicios sobre la Web misma \\
\hline Visualizaciones de página & Costo por clic & \\
\hline Directorios (por taxonomía) & $\begin{array}{l}\text { Etiquetado (por taxonomía } \\
\text { popular, sin jerarquías ni pre- } \\
\text { determinaciones) }\end{array}$ & $\begin{array}{l}\text { Inteligencia artificial para deci- } \\
\text { siones por interés del usuario }\end{array}$ \\
\hline Publicación & Participación & $\begin{array}{l}\text { Compartir, procesar y transfe- } \\
\text { rir ubicuamente información }\end{array}$ \\
\hline $\begin{array}{l}\text { Sistemas de manejo y gestión } \\
\text { de contenido ligados a publi- } \\
\text { cidad e ideologías }\end{array}$ & Enciclopedias colaborativas & Mapas temáticos automáticos \\
\hline Destacar un foro web & Redifusión en red & $\begin{array}{l}\text { Gestión de contenidos selec- } \\
\text { cionados por interpretación }\end{array}$ \\
\hline Especulación con dominios & $\frac{\text { Optimización en motores de }}{\text { búsqueda SEO }}$ & $\begin{array}{l}\text { Captura y tratamiento inteli- } \\
\text { gente de datos }\end{array}$ \\
\hline
\end{tabular}

Fuente: elaboración propia a partir de O’Reilly (2005), Van Der Henst (2005), y Bravo (2007).

Las dos tablas anteriores significan que la política puede tener avances tanto del lado de los electores representados como de los representantes políticos elegidos por los ciudadanos cuando se trata de crear cultura democrática. 


\section{El Estado e Internet}

Muchos vieron con agrado una revolución democrática por venir cuando la TIC, conocida como Internet, empezó a expandirse. En 1995, el Presidente de la Cámara de Representantes de EE. UU., Newt Gingrich, celebró la llegada de Internet a la política porque consideraba que con mayor acceso a la información y comunicación mejoraría la calidad del gobierno. Tres años después cada uno de los representantes en la Cámara de EE. UU. no sabía cómo atender y responder los 1000 correos electrónicos que en promedio recibían diariamente (Ault y Jones, 1999 y Jarvis y Wilkerson, 2005: 10). Esta realidad lleva directamente a la pregunta por el potencial democrático de Internet. Expertos como Hall (1999: 43) y Menéndez (2011: 75) intentan responder con tres posibilidades: la utópica, la realista pesimista y la utilitaria.

La posición utópica considera que la extensión de Internet a la vida pública actuará como una fuerza democratizadora que activará la participación, mientras los realistas pesimistas consideran que Internet ahondará las diferencias entre las masas empobrecidas e iletradas y también entre las regiones, razas y géneros, provocando, además, la globalización económica a la par del control autoritario. La actitud utilitaria presenta un balance entre las sociedades abiertas e incluyentes y las posibilidades de mayor control y limitación de la libertad. Reconoce también la capacidad para promover la democracia participativa al mejorar la comunicación entre ciudadanos y sus representantes políticos generando sentido de comunidad y capital social. Una cuarta posición puede encontrarse a lo largo de todo el ensayo de West (2005) quien no ve la relación entre el Gobierno e Internet como una revolución porque la historia muestra que muchas de las tecnologías, y particularmente las de la información, si bien presentan cambios relativamente acelerados, el alto impacto se da a largo plazo. West ejemplifica esto con el símil de los autos (2005: 8); cuando la industria automotriz nació se esperaba una revolución en el transporte, pero esta no fue rápida; de hecho por motivos económicos y técnicos muy pocas personas podían disponer de transporte automotriz. Pero con el paso de las décadas la industria automotriz prácticamente alcanzó casi a todas las civilizaciones y hoy día serían impensables sin la existencia del auto, autobuses y camiones. Hay razones suficientes para creer que pasará lo mismo con las tecnologías electrónicas de información y su vínculo con la gobernanza. De hecho, se le debe a West (2005: 11) la primera escala de etapas, modelo de cambio tecnológico y grados de calificación, que conocemos para graduar la participación de Internet en las acciones del Estado. Las etapas o grados de evolución para obtener una mejor calificación en la calidad de la gobernanza son: 1) la etapa de Billboard; los sitios Web publican informes y bases de datos pero no hay oportunidades para la interacción ciudadana porque no existe la comunicación bidireccional entre ciudadanos y funcionarios, 2) la etapa de presentación de servicios parciales, 3) la etapa del portal con la prestación de servicios en línea plena e integrada; el Gobierno gana confianza al ofrecer esta comodidad y, además, da la impresión de estandarización que evita la corrupción, 4) la cuarta etapa es la democracia interactiva con la difusión pública de rendición de cuentas y otras características para mejorar de la democracia. Como es notorio, las tres primeras etapas obedecen al E-gobierno y la última constituye el primer puente hacia la E-democracia. Atendamos a esta última. 
La E-democracia es más complicada que la simple administración de servicios públicos estatales, pues incide directamente en la definición, diseño, planeación, programación, presupuestación y evaluación de las decisiones del Estado en la esfera de las denominadas políticas públicas. En ella los primeros impactos de Internet generaron la disposición de grandes cantidades de información, el fomento de la descentralización y la diversidad. Los segundos efectos fueron la facilitación de la comunicación y la interacción. Efectos más recientes han tenido como consecuencia la generación de espacios deliberativos, todavía con límites y sin la velocidad instantánea del tiempo real. Sin embargo, hay que guardar un mesurado optimismo porque la Web por sí misma, si bien promueve la participación ciudadana, no genera de manera expedita cambios en los gobiernos. Lo anterior no implica una visión pesimista porque, como se ha dicho en la Tabla I, el uso e incremento de la Web provoca su perfeccionamiento, expansión y valor.

Lo cierto es que la proporción de espacios cibernéticos que abordan la esfera pública crece día con día e, inexorablemente, los new media con contenido político rebasan por mucho a los mass media tradicionales de contenidos similares, pues su capacidad de reciprocidad comunicativa fomenta las prácticas para convocar mítines, dirigir debates, coordinar y administrar actividades como la generación de opinión pública consensuada, la defensa de intereses, las negociaciones, movilizaciones, las acciones legales (denuncias, demandas, recursos de amparo, réplicas a tribunales, etc.), el trabajo en equipo, la firma de peticiones al gobierno, el reclutamiento de simpatizantes, la recolección de fondos, las alianzas estratégicas, el levantamiento de encuestas on line sobre conflictos o preferencias sociales y un largo etcétera, amén de todos los proselitismos electorales. La práctica, entonces, genera una mayor cultura digital que avanza hacia una cultura digital política. Ello ha llevado a proponer La cuarta generación de derechos humanos en las redes digitales (Bustamante, 2010). No es este el lugar de elaborar un catálogo de los mismos, el cual ha evolucionando desde hace más de una década y media, pero no se puede dejar de apuntar la apropiación social de la tecnología, la utilización de los new media para acceder universalmente y a bajo costo a la información y difusión de ideas, la promoción de la inclusión digital como la creación de inteligencia colectiva más allá de la adquisición de soportes informáticos, la protección frente a políticas de vigilancia y control de los usos legítimos de las nuevas tecnologías, el software libre para la interconexión de la esfera pública, y en lo referente al gobierno electrónico, el derecho a participar en el diseño y evaluación de los procedimientos gubernamentales electrónicos.

Por otra parte, no desconocemos la diferencia entre la mera existencia del medio electrónico y el reconocimiento jurídico de los derechos y formas de participación que a través de ellos puedan exigirse. No es lo mismo diseñar junto con la administración estatal los procesos de interacción, transacción e integración que tomar las decisiones co-legislativas y ejecutivas de las políticas públicas. Si la participación ciudadana se da a través de los new media no implica que el Estado se dejará influenciar sin resistencia. El instrumento cibernético no es suficiente para que el Estado legalice la participación y los mecanismos que buscan la obtención de derechos o satisfaga las demandas sociales desde el diseño de sus programas. Pero el medio electrónico propicia la realidad de un 
grupo de opinión de contrapeso a los poderes de facto; ahora como nunca podemos usar los nuevos instrumentos.

Si es cierto que la práctica hace costumbre y esta puede ser fuente del derecho, entonces podremos influir en el Estado con la estrategia que Queraltó (2000) llamó el caballo de Troya al revés. Se llama "al revés" porque en lugar de introducir enemigos soterradamente para destruir al Estado de Troya, lo hace para generar su construcción. Al introducir la práctica frecuente del uso de los new media, -aún por razones mercantilistas, de eficiencia y pragmática-, se introduce de manera silenciosa su rutina y ello deviene en la exigencia del derecho a la información, la comunicación y de ahí al derecho de la opinión pública y la participación ciudadana en las modalidades Web. Cuando las prácticas mediáticas están integradas a la vida diaria es imposible extirparlas y, por ende, excluirlas de la posibilidad democratizadora. Por lo tanto, los new media, además de abocarse a la justificación de nuevos derechos (especialmente de aquellos relacionados con el uso de sí mismos), ayudan a la implementación, uso político y técnico de los derechos fundamentales y sus derivados universales, constitucionales y diferenciados. Es decir, los artefactos, a pesar de aparentar ser neutros, sí hacen política al ejercer ciertas formas de poder (desde el informativo que se eleva hasta el demandante) que se traducen en pautas de la vida social que llegan a constituirse como autoridad.

\section{Conclusiones: Mucho navegar hace ciudadanos}

Cualquiera sea el tipo de participación ciudadana (reacción de protesta activista o participación ciudadana autónoma para influir y ejecutar acciones de orden estatal) en las diversas redes sociales se deberán enfrentar variadas restricciones. Dichas limitaciones podemos enumerarlas por categorías.

En la categoría económica existen las restricciones de accesibilidad: por ejemplo, en México el Instituto Nacional de Estadística y Geografía ([INEGI], 2011) indica que en 2011 solo el 32 \% de los hogares encuestados cuentan con conexión a Internet.

En la categoría cultural existe el límite de la proclividad: el INEGI reporta para el mismo período anteriormente citado que cada vez que se utiliza Internet solo el $41 \%$ hace conexiones con el Gobierno. También existe la limitación cultural por desesperanza; después de las reacciones de protesta en las redes sociales, las respuestas del Estado tardan en llegar y las demandas se diluyen; o para la sociedad mayoritaria del día a día las protestas resultan ajenas o tan innovadoras que provocan un rechazo generalizado. En efecto, la reacción de protesta es más intensa pero demasiado efímera o utópica comparada con la planeación programática. Otra limitación cultural es la carencia educativa, pues la mayoría de usuarios no tiene formación cívica suficiente para interesarse en la participación ciudadana más allá de las elecciones.

Una categoría más es la restricción jurídica, dado que la mayoría de los usuarios de Internet no posee formalmente derechos ciudadanos por ser menores de edad o migrantes no legalizados. 
A pesar de los límites de los new media, la participación en las redes sociales se distingue de la participación de antaño por la diversidad. El límite de la accesibilidad es real pero hoy en día la participación tiene mayores alcances en las clases sociales, los entornos educativos, y menos discriminación en las áreas de género, etnia, migración, etc. Es decir, integra a muchos más participantes que los mass media tradicionales.

Si a la expansión de accesibilidad por el software libre y la automultiplicación e inter-operatividad de la Web 3.0 añadimos el ambiente de "ubicuidad virtual", entonces los partidos políticos y los poderes de facto no tienen oportunidad de contrarrestar grupos de oposición, sectores subversivos descontentos, acciones anti-gubernamentales, o grupos minoritarios diferenciados, etc. Ello puede provocar que disminuyan la desesperanza y el desgaste participativo.

Por otra parte, las "reglas no escritas" propias de Internet impactan el modo autodidacto de conducirse en la Web y, por tanto, de la participación ciudadana. Entre esas "reglas no escritas" está la representatividad directa, horizontal, descentralizada y sin vínculos partidistas. Producto de lo anterior es una participación comunitaria en Internet que se acostumbra a un entorno democrático y exige mayor E-alfabetización y, al obtenerla, consigue más educación cívica. Así se forma un círculo virtuoso que abate los límites educativos y de deficiente proclividad política, a la vez que eleva los contenidos y la calidad de los debates ciudadanos.

La ruta aquí descrita puede narrarse como el camino que va de la información y movilización (Web-blogs y Twitters), pasando por la deliberación y protección, (Facebook), hacia la organización y colaboración (Web 3.0 federada), hasta las exigencias decisorias de mejores políticas y acciones públicas en el Congreso.

\section{Referencias bibliográficas}

Arthur, B. (1989). Competing technologies, increasing retums and lock-in by historical events. Economic Journal, 99 (3), 116-131.

Ault, A., and Jones, K. (1999). Three words Congress hates to hear: You've got mail. 5th est@te: Vote.com. Recuperado el 15 de enero, 2012 de http://www.vote.com/magazine/editorials/editorial1843752. phtml

Bravo, H. (2007). La Web 3.0, añade significado. Recuperado el 15 de enero, 2012 de: http://www. maestrosdelweb.com/editorial/la_-web_30_anade_significado/

Bustamante, J., (2010) La cuarta generación de derechos humanos en las redes sociales. Telos, Cuadernos de Comunicación e Innovación, 85, 80-89.

Crossley, N. (2002). Global Anti-Corporate Struggle: A Preliminary Analysis. British Journal of Sociology 53(4), 667-691.

Cullum, B. (2010). What makes a Twitter hashtag successful?. Movements.org, 17 Recuperado el 15 de enero, 2012 de http://www.movements.org/blog/entry/what-makes-a-twitter-hashtag-successful/

Hall, M. (1999). Virtual colonization. Journal of Material Culture, (4), 39- 55. 
Henríquez, M. (2011). Clic Activismo: redes virtuales, movimientos sociales y participación política. Faro, Revista Teórica de la Facultad de Ciencia Sociales, (13). Recuperado el 15 de enero, 2012 de http:// web.upla.cl/revistafaro/n13/art04.htm

INEGI (2011) Encuesta Nacional sobre la Percepción Pública de la Ciencia y la Tecnología en México. Recuperado el 15 de enero, 2012 de http://www.siicyt.gob.mx/siicyt/docs/Encuestas/ SintesisMetodologica-Enpecyt-2011.pdf

Jarvis, S. and Wilkerson, K. (2005). Congress on the Internet: Messages on the Home pages of the US House of Representatives, 1996 and 2001. Journal of Computer Mediated Communication, 10, (2), 10: 00. doi: 10.1111/j.1083-6101.2005.tb00246.x Indiana. Recuperado el 15 de enero, 2012 de http://jicmc. indiana.edu/vollo/Issue2/jarvis.html

Jenkins, H. (2010). Perhaps a revolution is not what we need. Recuperado el 15 de enero, 2012 de http://henryjenkins.org/2010/10/perhaps_a revolution_is_not_wh.html

Jollivet, P. (2004). Anexo 2: Los rendimientos crecientes. En O. Blondeau y otros, Capitalismo cognitivo, propiedad intelectual y creación colectiva (pp. 127-152). Madrid: Traficantes de Sueños.

Gladwell, M. (2010). Small Change: Why the Revolution Will Not Be Tweeted. Recuperado el 15 de enero, 2012 de http://www.newyorker.com/reporting/2010/10/04/101004fa _ fact _ gladwell

Menéndez, M. (2011). Las redes sociales y su efecto político. Telos, Cuadernos de Comunicación e Innovación, $89,74-83$

Metcalfe, R. y Boggs, D. (1976). Ethernet: distributed packet switching for local computer network. Communications of the ACM (Association for Computing Machinery), 19 (7), 395-404.

O'Reilly, T. (2005). What Is Web 2.0 Design Patterns and Business Models for the Next Generation of Software. Recuperado el 15 de enero, 2012 de http://oreilly.com/web2/archive/what-is-web-20.html.

Postill, J. (2011). Localizing the Internet: An Anthropological Account.

Oxford: Berghahn.

Postill, J. (2012). Follow their interests: the ethnography of microblogging as a protest practice. Paper to the \#IR13 Conference Salford University, UK. Recuperado el 15 de enero, 2012 de http://www. academia.edu/2046671/Follow_their_interests_the_ethnography_of microblogging as_a a protest_practice

Queraltó, R., (2000) El caballo de Troya al revés: diseño de una estrategia ética en la sociedad tecnológica, en Actas del III Congreso de la Sociedad de Lógica, Metodología y Filosofía de la Ciencia en España, 301-308.

Rosen, J. (2005). The Weblog: An Extremely Democratic Form in Journalism, Recuperado el 15 de enero, 2012 de http://extremedemocracy.com/chapters/Rosen _weblog.pdf.

Srinivasan, R. and Fish, A. (2009). Internet Authorship: Social and Political Implications Within Kyrgyzstan. J. Computer-Mediated Communication 14 (3), 559-580.

Van Der Henst, Ch. (2005). ¿Qué es la Web 2.0? Recuperado el 15 de enero, 2012 de http://www. maestrosdelweb.com/editorial/web2/

Vattimo, G. (1990). La sociedad transparente. Barcelona: Paidós.

West, D. (2005). Digital Government: Technology and Public Sector Performance. Princeton: Princeton University Press. 